Original article

\title{
DIAGNOSTIC AND PROGNOSTIC SIGNIFICANCE OF SERUM GASTRIN AND PEPSINOGEN IN DAIRY COWS WITH DISPLACED ABOMASUM
}

\author{
A. KHALPHALLAH ${ }^{1}$, E. ELMELIGY ${ }^{2}$, A. A. AAMER ${ }^{1}$, T. ABDELALL ${ }^{1}$, \\ S. OIKAWA ${ }^{3} \&$ K. NAKADA ${ }^{3}$ \\ ${ }^{1}$ Department of Animal Medicine, Faculty of Veterinary Medicine, Assiut \\ University, Egypt; ${ }^{2}$ Veterinary Teaching Hospital, Faculty of Veterinary Medicine, \\ Assiut University, Egypt; ${ }^{3}$ Department of Veterinary Herd Health, School of \\ Veterinary Medicine, Rakuno Gakuen University, Ebetsu, Hokkaido, Japan
}

\section{Summary}

Khalphallah, A., E. Elmeligy, A. A. Aamer, T. AbdelAll, S. Oikawa \& K. Nakada, 2018. Diagnostic and prognostic significance of serum gastrin and pepsinogen in dairy cows with displaced abomasum. Bulg. J. Vet. Med., 21, No 1, 67-75.

The study aimed to describe the changes in clinical findings and serum levels of gastrin, pepsinogen and chloride $(\mathrm{Cl})$ in dairy cattle with displacement of the abomasum (DA) from day 0 until day 30 after surgery and to evaluate their diagnostic and prognostic value in evaluation of the abomasal function. The study was conducted on DA cattle $(n=25)$ belonging to dairy farms in Hokkaido area, Japan. Cows were examined and sampled at days 0 (surgery), 7 and 30. Based on blood $\beta$-hydroxybutyric acid (BHBA) at day 0 , DA cows were classified into three categories; DA only $(<1.2 \mathrm{mmol} / \mathrm{L})$, DA with subclinical ketosis (DA SCK: $1.2-2.4 \mathrm{mmol} / \mathrm{L}$ ) and DA with clinical ketosis (DA CK: $\geq 2.5$ $\mathrm{mmol} / \mathrm{L}$ ). All DA groups had higher serum gastrin than their physiological reference values in cattle both before or after surgery. Serum gastrin was significantly increased $(\mathrm{P}<0.05)$ in DA and DA SCK groups particularly at day 30 vs day 0 . Serum pepsinogen and chlorides were not remarkably changed in any of the three diseased groups compared to reference values. Serum pepsinogen showed no significant within- and inter-group changes. The surgery and the 30-day follow-up period were not sufficient to serum gastrin to return to its physiological levels. In conclusion, further future studies may be required to investigate serum gastrin levels change in DA cattle. A longer follow up period up to 45 day is suggested.

Key words: dairy cattle, displaced abomasum, gastrin, pepsinogen

\section{INTRODUCTION}

Displacement of the abomasum (DA) is a common and economically important problem of dairy cattle in early lactation. Affected cows produce less milk at least in the short term (Raizman \& Santos 2002; Van Winden \& Kuiper, 2003; Radostits et al., 2007) and have a higher culling rate (Gröhn et al., 1998; Raizman 
Diagnostic and prognostic significance of serum gastrin and pepsinogen in dairy cows with ....

\& Santos 2002; Radostits et al., 2007) that may reach $10 \%$ (Van Winden \& Kuiper, 2003).

Current treatment costs range from $\$ 100$ to $\$ 200$ per case. $10 \%$ of the cows that are diagnosed with DA are culled or die before the next test day. Treated cows that remain in the herd produce $350 \mathrm{~kg}$ less milk the next month than cows without DA (Eicker, 1995).

Clinically, left displaced abomasum (LDA) characterised by gas accumulation in the abomasum resulting in a tympanic, resonant and high-toned ping sound (Breukink \& Kroneman, 1963). Furthermore, diseased cows with DA were febrile with tachycardia, increased respiratory rates and ruminal hypomotility (El-Attar et al., 2007).

Strong associations have been stated between many of the post partum diseases and increase the risk of DA. Several studies reported twins, dystocia, milk fever, retained placenta, metritis, and ketosis as risk factors for LDA (Gröhn et al., 1998; Gröhn, 2000; LeBlanc et al., 2005).

Some studies reported the most common clinical findings and metabolic profiles associated with DA in dairy cattle (Stengärde et al., 2010), DA and ketosis (Stengärde et al., 2008). Furthermore, serum changes of pepsinogen (Mesarič et al., 2002; Abouzeid et al., 2008), gastrin (Ozturk et al., 2013) and chloride (Cl) (Mokhber Dezfouli et al., 2013; Ozturk et al., 2013) in DA cows were also reported, however they did not discuss the clinical and biochemical changes associated with DA cows until the animals get recovered after surgical interference.

Accordingly, the current work described the pattern of changes through following up the clinical findings, milk losses, culling rate, complicated diseases and serum biochemicals including pepsi- nogen and gastrin in dairy cattle with DA from day 0 before surgery until post operative day 30 . The study also focused on the diagnostic and prognostic value of serum levels of gastrin, pepsinogen and chlorides in abomasal function evaluation in dairy cows with regard to their importance to recovery.

\section{MATERIALS AND METHODS}

\section{Experimental design}

The study was conducted on DA cattle $(n=25)$ from dairy farms in Hokkaido area, Japan. DA cattle were treated surgically and by medicaments including i.v. fluid therapy with $1 \mathrm{~L}$ Ringer solution and $500 \mathrm{~mL} \mathrm{25 \%}$ glucose, and penicillin at surgery (day 0). Cows were sampled at days 0 (surgery), 7 and 30. Based on blood BHBA at day 0, DA cows were classified into three categories; DA only $(\mathrm{n}=8 ;<1.2 \mathrm{mmol} / \mathrm{L})$, DA with subclinical ketosis (DA SCK; $\mathrm{n}=10 ; 1.2-2.4 \mathrm{mmol} / \mathrm{L}$ ) and DA with clinical ketosis (DA CK; $\mathrm{n}=7 ; \geq 2.5 \mathrm{mmol} / \mathrm{L})$. All cattle were treated under the Laboratory Animal Control Guidelines of Rakuno Gakuen University, which basically conform to the Guide for the Care and Use of Laboratory Animals of the National Institutes of Health in the USA (NIH publication No. 86-23, revised 1996).

In this study, $44 \%$ (11 of 25$)$ of DA cases were reported in the $1^{\text {st }}$ week after calving or 1-7 days in milk (DIM), 52\% (13 of 25 ) occurred in the $2^{\text {nd }}$ and $3^{\text {rd }}$ weeks post calving (8-21 DIM) and only one cow (4\%) was diagnosed at 128 DIM with right displaced abomasum with abomasal volvulus (RDA with AV). About 84 $\%$ (21 of 25$)$ of the DA cases were with left displaced abomasum (LDA) and 16\% (4 of 25) - with RDA. 


\section{Blood samples and analyses}

Clinical examination of all dairy cattle using clinical chart according to Rosenberger (1990) was done. Body condition score (BCS) of all cows was estimated based on a 5-point scale (Ferguson et al., 1994). Rates of milk losses, culling rate and predisposing factors and complicated diseases associated with DA cases in the three diseased groups were investigated.

Blood samples were collected from the jugular vein into plain vacutainer tubes, and then were centrifuged at $3000 \times \mathrm{g}$ for $15 \mathrm{~min}$. Sera were separated and stored at $-20{ }^{\circ} \mathrm{C}$ until analysis. Clinical examination and estimation of serum biochemicals were conducted 3 times; days 0,7 and 30 .

Serum gastrin levels were determined by double antibody gastrin ${ }^{125} \mathrm{I}$ radioimmunoassay (RIA Kit, DPC, USA) according to Kataria et al. (2008).

The serum pepsinogen value was measured by the colorimetric method of Edwards et al. (1960) with modifications (Mylrea \& Hotson, 1969; Berghen et al., 1987). Plasma was added to a substrate mixture $(0.9 \%$ bovine albumin fraction $\mathrm{V}$ in glycine buffer, $\mathrm{pH} 2.0$ ) and mixed thoroughly. An aliquot of this mixture was incubated in a water bath at $37{ }^{\circ} \mathrm{C}$ for 24 $\mathrm{h}$. Then reaction was stopped by adding 4\% trichloroacetic acid solution (Mylrea \& Hotson, 1969). After filtration of the protein precipitate the concentration of acid soluble tyrosine was determined by Folin Coicalteau's reagent. For this purpose, $0.5 \mathrm{~mL}$ of Folin Coicalteau's reagent and $10 \mathrm{~mL}$ of $0.25 \mathrm{~N}$ sodium hydroxide were added to $2 \mathrm{~mL}$ of filtrate. Two $\mathrm{mL}$ of tyrosine standard was also treated in the same way. The optical density was read at $680 \mathrm{~nm}$ wavelength using a spectrophotometer (GeneQuant 100, GE healthcare, Japan). The enzyme activity was expressed as milli-units (mU) tyrosine (Reid et al., 1967).

Serum chlorides were determined by atomic absorption spectrophotometer with an autoanalyzer (Shimadzu Model AA 6200, Tokyo, Japan).

\section{Statistical analysis}

All statistical analyses were performed using Computer Soft Ware (SPSS version 17.0, Chicago, USA). The data obtained from clinical examination and biochemical analyses were analyzed by analysis of variance (ANOVA). The significance of differences between the means at selected sampling days (days 7 and 30) and day 0 was in each DA group evaluated by Dunnett's test. The significance of differences between the means at diseased groups (DA SCK and DA CK) at sampling days; 0,7 and 30 , and DA group in the same parallel days evaluated by Dunnett's test were expressed as means $\pm \mathrm{SD}$ at $\mathrm{P}<0.05$ (Spsswin, 1997).

\section{RESULTS}

The obtained results revealed that $29.41 \%$ and $70.59 \%$ of LDA cases happened in the $1^{\text {st }}$, and the $2^{\text {nd }}$ and $3^{\text {rd }}$ weeks of lactation, respectively. $50 \%, 25 \%$ and $25 \%$ of the RDA cases were reported in the $1^{\text {st }}$ week, the $2^{\text {nd }}$ and $3^{\text {rd }}$ weeks of lactation, and 128 DIM, respectively.

The culling rate of the examined cows was $16 \%$ (4 of 25 ). The rates of milk loss were $233.45 \pm 73.53,217.91 \pm 81.38$ and $291 \pm 72.52 \mathrm{~kg}$ in DA, DA SCK and DA $\mathrm{CK}$, respectively.

Many parturient diseases $-64 \%$ (16 of 25 ) were considered as predisposing factors for DA in dairy cows - ketosis, retained placenta, milk fever, mastitis and metritis. They were also considered as complication of DA $(56 \% ; 14$ of 25$)$. 
Diagnostic and prognostic significance of serum gastrin and pepsinogen in dairy cows with ....

The clinical parameters (temperature, pulse and respiratory rate) in DA groups were within the physiological reference range. Ruminal movements were reduced in the diseased cows at day 0 then after the surgical correction of DA they improved at days 7 and 30. BCS (Table 1) showed no significant changes neither between the diseased groups (DA SCK or DA CK) when their values compared with those of DA group at days 0,7 and 30, nor within each DA group when their values at days 7 and 30 compared with those at day 0 . BCS was still within the physiological reference values.
Serum pepsinogen concentrations (Table 2) were not remarkably changed neither at days 7 or 30 in each of DA groups vs day 0 , nor between the diseased groups. They were within the physiological reference values.

The reported results mentioned that serum gastrin levels (Table 3) in all DA cases throughout the present study either before or after operation were higher than the physiological reference values of blood gastrin in cows. Serum gastrin was significantly increased $(\mathrm{P}<0.05)$ in $\mathrm{DA}$ group at days 7 and 30, and DA SCK group at day 30 as compared with those in

Table 1. Body condition scores in cows with displaced abomasum (DA), displaced abomasum with subclinical ketosis (DA SCK) and displaced abomasum with clinical ketosis (DA CK) at surgery (day 0 ) and at post operative days 7 and 30 . Data are presented as mean \pm SD

\begin{tabular}{lccc}
\hline & Day 0 & Day 7 & Day 30 \\
\hline DA group $(\mathrm{n}=8)$ & $3.06 \pm 0.50$ & $3.0 \pm 0.40$ & $2.88 \pm 0.38$ \\
DA SCK group $(\mathrm{n}=10)$ & $3.20 \pm 0.48$ & $3.13 \pm 0.32$ & $3.00 \pm 0.24$ \\
DA CK group $(\mathrm{n}=7)$ & $3.07 \pm 0.37$ & $2.96 \pm 0.17$ & $2.82 \pm 0.24$ \\
\hline
\end{tabular}

Table 2. Serum pepsinogen $(\mathrm{mU})$ in cows with displaced abomasum (DA), displaced abomasum with subclinical ketosis (DA SCK) and displaced abomasum with clinical ketosis (DA CK) at surgery (day 0 ) and at post operative days 7 and 30 . Data are presented as mean \pm SD

\begin{tabular}{lccc}
\hline & Day 0 & Day 7 & Day 30 \\
\hline DA group $(\mathrm{n}=8)$ & $1193.33 \pm 263.67$ & $960.15 \pm 319.30$ & $1102.76 \pm 257.70$ \\
DA SCK group $(\mathrm{n}=10)$ & $1002.50 \pm 260.16$ & $1002.32 \pm 318.53$ & $885.62 \pm 178.07$ \\
DA CK group $(\mathrm{n}=7)$ & $878.15 \pm 251.83$ & $915.98 \pm 184.89$ & $1056.08 \pm 273.03$ \\
\hline
\end{tabular}

Table 3. Serum gastrin (ng/L) in cows with displaced abomasum (DA), displaced abomasum with subclinical ketosis (DA SCK) and displaced abomasum with clinical ketosis (DA CK) at surgery (day 0 ) and at post operative days 7 and 30 . Data are presented as mean $\pm \mathrm{SD}$

\begin{tabular}{lrrr}
\hline & Day 0 & \multicolumn{1}{c}{ Day 7} & \multicolumn{1}{c}{ Day 30} \\
\hline DA group $(n=8)$ & $195.00 \pm 30.88$ & $323.00 \pm 91.63^{* *}$ & $434.25 \pm 73.81^{* *}$ \\
DA SCK group $(n=10)$ & $199.56 \pm 90.86$ & $262.25 \pm 77.43$ & $337.78 \pm 59.24^{* *}$ \\
DA CK group $(n=7)$ & $239.00 \pm 91.24$ & $463.50 \pm 263.07$ & $499.83 \pm 206.94$ \\
\hline
\end{tabular}

${ }^{*} \mathrm{P}<0.05 ; * * \mathrm{P}<0.01$ compared with the value at day 0 in each DA group. 
Table 4. Serum chlorides $(\mathrm{mmol} / \mathrm{L})$ in cows with displaced abomasum (DA), displaced abomasum with subclinical ketosis (DA SCK) and displaced abomasum with clinical ketosis (DA CK) at surgery (day 0 ) and at post operative days 7 and 30 . Data are presented as mean \pm SD

\begin{tabular}{lccc}
\hline & Day 0 & Day 7 & Day 30 \\
\hline DA group $(n=8)$ & $97.50 \pm 6.41$ & $99.38 \pm 3.11$ & $93.63 \pm 14.09$ \\
DA SCK group $(n=10)$ & $97.40 \pm 7.37$ & $101.30 \pm 4.85$ & $95.80 \pm 13.91$ \\
DA CK group $(n=7)$ & $96.57 \pm 3.05$ & $101.00 \pm 3.83$ & $101.67 \pm 5.05$ \\
\hline
\end{tabular}

day 0. Gastrin concentrations were not remarkably changed in DA CK group throughout the study, however they started to increase gradually after the surgery until day 30 but this increase was insignificant. Serum gastrin showed no significant changes between DA groups when their values in DA group were compared with those in the other two groups on days 0,7 or 30 .

There were no significant changes in serum levels of chlorides (Table 4) which were within the reference ranges during the entire period of the study.

\section{DISCUSSION}

The current study stated that DA caused economic losses in DA, DA SCK and DA CK groups, due to milk loss, increased treatment costs and culling rates. Other studies also report that $10 \%$ of cows with DA are culled or die (Van Winden \& Kuiper, 2003). The DA cattle produce less milk at least in the short term (Raizman \& Santos, 2002) and have a higher culling rate (Raizman \& Santos, 2002; Van Winden \& Kuiper, 2003).

DA in the present study is a common disease of dairy cattle in early lactation with in the first 3 weeks post-calving; $44 \%$ in the $1^{\text {st }}$ week, $52 \%$ occurred in the next 2 weeks. Previous reports mention that LDA commonly occurs in the postpartum period (3 to 7 weeks postpartum)
(Rohn et al., 2004) and most frequently in highly lactating dairy cows during early lactation (Veysi et al., 2003; El-Attar et al., 2007).

The obtained results revealed that occurrence rates of LDA and RDA were about $84 \%$ and $16 \%$, respectively in agreement with reports indicating that 80 to $90 \%$ of all DA are left-sided (Guard, 1990; Pehrson \& Shaver, 1992). Also, 80 to $90 \%$ of LDA are diagnosed within $1^{\text {st }}$ month after calving (Pehrson \& Shaver, 1992).

The current study stated that $29.41 \%$ and $70.59 \%$ of LDA cases happened in the $1^{\text {st }}$, and in the $2^{\text {nd }}$ and $3^{\text {rd }}$ weeks of lactation, respectively. $50 \%, 25 \%$ and $25 \%$ of the RDA cases were reported in the $1^{\text {st }}$ week, the $2^{\text {nd }}$ and $3^{\text {rd }}$ weeks of lactation, and 128 DIM, respectively. It has been acknowledged that the LDA and RDA were encountered within 6 weeks (Radostits et al., 2007) and 3-6 weeks after parturition (Delgado-Lecaroz et al., 2000), respectively.

Many postparturient diseases in the present study were considered as predisposing factors for DA in dairy cows; $64 \%$ of DA cases were associated with these diseases. These diseases included ketosis, retained placenta, milk fever, mastitis and metritis. Other studies also reported an association of ketosis, hypocalcaemia and milk fever with DA (Massey et al., 1993; Oikawa et al., 1997; Care et al., 1999). 
Duffield \& Bagg (2002) also added that herds with ketosis in early lactation cows were at risk of increased incidence of DA $(>8 \%)$ and increased herd removals in the first 60 DIM $(<8 \%)$.

The current study also found out that $56 \%$ of DA cases were complicated by ketosis, milk fever, retained placenta, metritis and/or mastitis. DA increases the risk of other postpartum disorders. This agreed with Curtis et al. (1985), Radostits et al. (2007) who mentioned that dairy cattle with LDA were at increased risk for ketosis and metritis.

The clinical findings in all DA cases showed no significant changes in temperature, pulse, respiratory rates and BCS neither between the diseased groups nor within each DA group. All these findings were within the physiological reference range reported by Ferguson et al. (1994) and Radostits et al. (2000). On the other hand, cows with DA were reported to be febrile with increased heart and respiratory rates, ruminal hypomotility (El-Attar et al., 2007), anorexia and reduced milk yield (Ozturk et al., 2013).

The obtained results stated no significant changes in BCS in all DA cases neither before or after surgical treatment of DA. BCS was not associated with a risk of LDA. The same was demonstrated by LeBlanc et al. (2005) who observed that prepartum BCS was not associated with a risk of LDA. Other studies reported that cows with excess BCS at calving are at increased risk for LDA (Dyk, 1995).

Serum pepsinogen levels in the three DA groups were within the physiological reverence values mentioned by Ohwada et al. (2002). The present study also indicated that serum pepsinogen showed no significant changes between the diseased DA groups. On the other hand, cows with abomasitis, LDA, RDA and abomasal ulcers have increased serum pepsinogen levels (Mesarič et al., 2002). Hajimohammadi et al. (2010) confirmed that serum pepsinogen levels were significantly higher in LDA and RDA affected sheep (investigated as a model for cattle). In contrast, Ohwada et al. (2002) proved that serum pepsinogen concentrations in LDA, RDA and AV cows were significantly decreased compared with healthy cows. Abouzeid et al. (2008) also mentioned that the pepsinogen values in all cows with DA at day 0 were remarkably decreased compared to the reference range. Moreover, there were no significant differences among cows with LDA, RDA and $\mathrm{AV}$.

All DA cases throughout this study had higher serum gastrin concentrations than physiological reference values mentioned by Ok et al. (2001). both before or after surgery. This may indicate that the operation and 30-day follow-up period were not long enough until for restoration of gastrin to its physiological levels. Serum gastrin was significantly increased in DA group and DA SCK group particularly at day 30 vs day 0 , but not remarkably changed in DA CK although it started to increase gradually but insignificantly until day 30. Ozturk et al. (2013) reported proofs for increased serum gastrointestinal motility and hormone concentrations including ghrelin, motilin and gastrin in cattle with DA.

The current study reported no significant changes in serum chlorides neither between the diseased DA groups nor within each DA group. Chloride concentrations were within the physiological reference ranges (Radostits et al., 2007). In contrast, it was reported that cows with DA or AV were associated with hypokalemia (Constable et al., 2013; Mokhber Dezfouli et al., 2013), hypochloremia 
(Radostits et al., 2000; Abouzeid et al., 2008; Mokhber Dezfouli et al., 2013) and low feed intake (Constable et al., 2013). Ozturk et al. (2013) mentioned that cattle with DA had low serum $\mathrm{Cl}$ concentrations.

\section{CONCLUSION}

In this study there were no other prominent significant changes either clinically (BCS) or biochemically (serum pepsinogen and chlorides) either in each DA group or between the diseased groups. Pepsinogen and chloride levels were within the physiological reference ranges. Serum gastrin concentration were higher than the physiological reference values throughout the current study indicating that the 30 day follow up period was not long enough to allow for full restoration of the physiological gastrin level and for complete recovery of the abomasal mucosa. Further studies may be required to investigate serum gastrin levels in cattle with displaced abomasum, suggesting a longer follow-up period up to the $45^{\text {th }}$ post operative day.

\section{ACKNOWLEDGEMENTS}

The authors are grateful to both of Ministry of higher education in Egypt and staff members of Herd Health Department, School of Veterinary Medicine, Rakuno Gakuen University, Ebetsu, Hokkaido, Japan, for their kind support during conducting this study.

\section{REFERENCES}

Abouzeid, N. Z., E. Sakuta, T. Kawai, T. Takahashi, A. Gotoh, K. Takehana, G. R. Oetzelshin \& S. Oikawa, 2008. Assessment of serum pepsinogen and other biochemical parameters in dairy cows with displaced abomasum or abomasal volvulus before and after operation. Journal of Rakuno Gakuen University, 32, 161-167.

Berghen, P., P. Dorny \& J. Vercruysse, 1987. Evaluation of a simplified blood pepsinogen assay. American Journal of Veterinary Research, 48, 664-669.

Breukink, H. J. \& J. Kroneman, 1963. Een nieuw diagnostisch hulpmiddel bij het onderzoek van het rund op de aanwezigheid van een gedilateerde en/of gedisloceerde lebmaag; het zgn. "Steelbandeffect". Tijdschrift voor Diergeneeskunde, 88, 282-291.

Care, A. D., S. K. Abbas, J. Harmeyer \& R. Boivin, 1999. The relaxant effects of parathyroid hormone (1-34) and parathyroid hormone-related protein (1-34) on ovine reticulo-ruminal smooth muscle in vivo. Experimental Physiology, 84, 665-675.

Constable, P. D., W. Grünberg, R. Staufenbiel \& H. R. Stämpfli, 2013. Clinicopathologic variables associated with hypokalemia in lactating dairy cows with abomasal displacement or volvulus. Journal of American Veterinary Medical Association, 242 , 826-835.

Curtis, C. R., H. N. Erb, C. J. Sniffen, R. D. Smith \& D. S. Kronfeld, 1985. Path analysis of dry period nutrition, postpartum metabolism and reproductive disorders, and mastitis in Holstein cows. Journal of Dairy Science, 68, 2347-2360.

Delgado-Lecaroz, R., L. D. Warnick, C. L. Guard, M. C. Smith \& D. A. Barry, 2000. Crosssectional study of the association of abomasal displacement or volvulus with serum electrolyte and mineral concentrations in dairy cows. Canadian Veterinary Journal, 41, 301-305.

Duffield, T. \& R. Bagg, 2002. Herd level indicators for the prediction of high-risk dairy herds for subclinical ketosis. In: Proceedings of the American Association of Bovine Practitioners, 35, 175-176.

Dyk, P. B., 1995. The association of prepartum non-esterified fatty acids and body condition with peripartum health problems on 95 Michigan dairy farms. M.S. Thesis, Michigan State University, East Lansing. 
Diagnostic and prognostic significance of serum gastrin and pepsinogen in dairy cows with ....

Edwards, K., R. P. Jepson \& K. F. Wood, 1960. Value of plasma pepsinogen estimation. British Medical Journal, 5165, 30 32.

Eicker, S. W., 1995. Milk production loss after displaced abomasum disease in New York Holsteins. The American Dairy Science Association Supplement, 1, 169.

El-Attar, H. M., M. Yassein, Abd El-Raof \& M. M. Ghanem, 2007. Alterations in the clinical, hematological and biochemical pictures in abomasal displacement in cows in Egypt. Veterinary Medical Journal, 16, 102-109.

Ferguson, J. D., D. T. Galligan \& N. Thomsen, 1994. Principal descriptors of body condition score in Holstein cows. Journal of Dairy Science, 77, 2695-2703.

Gröhn, Y. T., 2000. Milk yield and disease: Towards optimizing dairy herd health and management decisions. Bovine Practice, 34, 32-40.

Gröhn, Y. T., S. W. Eicker, V. Ducrocq \& J. A. Hertl, 1998. Effect of diseases on the culling of Holstein dairy cows in New York state. Journal of Dairy Science, 81, 966-978.

Guard, C., 1990. Large Animal Internal Medicine, ed B. P. Smith, Mosby Co., St. Louis, MO, pp. 792.

Hajimohammadi, A., K. Badiei, K. Mostaghni \& M. Pourjafar, 2010. Serum pepsinogen level and abomasal ulcerations in experimental abomasal displacement in sheep. Veterinarni Medicina, 55, 311-317.

Kataria, N., A. K. Kataria \& A. K Gahlot, 2008. Use of plasma gastrin and pepsinogen levels as diagnostic markers of abomasal dysfunction in marwari sheep of arid tract. Slovenian Veterinary Research, $\mathbf{4 5}$, 121-126.

LeBlanc, S. J., K. E. Leslie \& T. F. Duffield, 2005. Metabolic predictors of displaced abomasum in dairy cattle. Journal of Dairy Science, 88, 159-170.

Massey, C. D., C. Wang, G. A. Donovan \& D. K. Beede, 1993. Hypocalcemia at parturi- tion as a risk factor for left displacement of the abomasum in dairy cows. Journal of American Veterinary Medical Association, 203, 852-853.

Mesarič, M., T. Zadnik \& M. Klinkon, 2002. Comparison of serum pepsinogen activity between enzootic bovine leukosis (EBL) positive beef cattle and cows with abomasal ulcers. Slovenian Veterinary Research, 39, 227-232.

Mokhber Dezfouli, M., Z. Eftekhari, S. Sadeghian, A. Bahounar \& M. Jeloudari, 2013. Evaluation of hematological and biochemical profiles on dairy cows with left displacement of the abomasum. Comparative Clinical Pathology, 22, 175-179.

Mylrea P. J. \& I. K. Hotson, 1969. Serum pepsinogen activity and the diagnosis of bovine ostertagiasis. British Veterinary Journal, 125, 379-388.

Oikawa, S., N. Katoh, F. Kawawa \& O. Yasushi, 1997. Decreased serum apolipoprotein B-100 and A-I concentrations in cows with ketosis and left displacement of the abomasum. American Journal of Veterinary Research, 58, 121-125.

Ohwada, S., S. Oikawa, F. Mori, M. Koiwa, A. Nitanai, T. Kurosawa \& H. Sato, 2002. Serum pepsinogen concentrations in healthy cows and their diagnostic significance with abomasal diseases. Journal of Rakuno Gakuen University, 26, 289-293.

Ok, M., I. Sen, K. Turgut \& K. Irmak, 2001. Plasma gastrin activity and the diagnosis of bleeding abomasal ulcers in cattle. Journal of Veterinary Medicine Series A, 48, 563-568.

Ozturk, A. S., M. Guzel, T. K. Askar \& I. Aytekin, 2013. Evaluation of the hormones responsible for the gastrointestinal motility in cattle with displacement of the abomasum; ghrelin, motilin and gastrin. The Veterinary Record, 172, 624.

Pehrson, B. G. \& R. D. Shaver, 1992. Displaced abomasum: Clinical data and effects of peripartal feeding and management on incidence. In: Proceedings of the American Association of Bovine Practitio- 
ners World Buiatrics Congress, St. Paul, $\mathrm{MN}$, American Association of Bovine Practitioners, Stillwater, OK, p. 116.

Radostits, O. M., C. C. Gay, D. C. Blood \& K. W. Hinchcliff, 2000. Veterinary Medicine: A Textbook of the Diseases of Cattle, Sheep, Pigs, Goats and Horses, $9^{\text {th }}$ edn., W. B. Saunders, London.

Radostits, O. M., C.C. Gay, K. W. Hinchcliff \& P. D. Constable, 2007. Diseases of the alimentary tract II. Left-side displacement of the abomasum and right-side displacement of the abomasum and abomasal volvulus. In: Veterinary Medicine: A Textbook of the Diseases of Cattle, Horses, Sheep, Pigs, and Goats. $10^{\text {th }}$ edn., Saunders Elsevier, London.

Raizman, E. A. \& J. E. P. Santos, 2002. The effect of left displacement of abomasum corrected by toggle-pin suture on lactation, reproduction, and health of Holstein dairy cows. Journal of Dairy Science, 85, 1157 1164.

Reid, J. F. S., J. Armour, F. W. Jennings, K. S. Kirkpatrick, G. M. Urquhart, 1967. The fascioliasis/ostertagiasis complex in young cattle: a guide to diagnosis and therapy. The Veterinary Record, 80, 371-374.

Rohn, M., B. A Tenhagen \& W. Hofmann, 2004. Survival of dairy cows after surgery to correct abomasal displacement: 2. Association of clinical and laboratory parameters with survival in cows with left abomasal displacement. Journal of Veterinary Medicine Series A, 51, 300-305.

Rosenberger, G., 1990. Die Klinische Untersuchung des Rindes, eds G. von Dirksen, H. D. Gründer \& M. S. Stöber, Verlag Paul Parey, Berlin and Hamburg, pp. 670677.

Spsswin, 1997. Software program for statistical analysis under Windows, USA.
Stengärde, L., M. Tråvén, U. Emanuelson, K. Holtenius, J. Hultgren \& R. Niskanen, 2008. Metabolic profiles around calving in five high-producing Swedish dairy herds with a history of abomasal displacement and ketosis. Acta Veterinaria Scandinavi$c a, \mathbf{5 0}, 31$.

Stengärde, L. U., K. Holtenius, M. Tråvén, J. Hultgren, R. Niskanen \& U. Emanuelson, 2010. Blood profiles in dairy cows with displaced abomasum. Journal of Dairy Science, 93, 4691-4699.

Van Winden, S. C. L . \& R. Kuiper, 2003. Left displacement of the abomasum in dairy cattle: recent developments in epidemiological and etiological aspects. Veterinary Research, 34, 47-56.

Veysi, A., O. K. Mahmut, B. Murat, S. Ismail, M. B. Fatih \& A. Fahrettin, 2003. The study on the relationship of abomasal displacement and fatty liver syndrome in dairy cows (Abstracts), $11^{\text {th }}$ International Conference on Production Diseases in Farm Animals. Acta Veterinaria Scandinavica, 44, suppl. 1.

Paper received 01.06.2016; accepted for publication 30.09.2016

\section{Correspondence:}

Arafat Khalphallah, DVM, PhD

Department of Animal Medicine, Faculty of Veterinary Medicine,

Assiut University,

Assiut 71526, Egypt

tel. +2021283888020

fax: +20882366503

e-mail: arafatvet2003@yahoo.com 